\title{
REVOLVING STOOL WITH BACK REST AN ERGONOMIC INTERVENTION FOR WOMEN IN JAGGERY BALL MAKING AGRO BASED ENTERPRISE
}

\author{
*PARIMALAM. $\mathbf{P}^{1} \&$ S. LOGESWARI ${ }^{2}$ \\ ${ }^{I}$ Professor and Head, Department of Family Resource Management and Consumer Science, \\ Community Science College and Research Institute, TNAU, Madurai,India \\ ${ }^{2}$ Research Associate (AICRP on Home Science), Department of Family Resource Management and Consumer Science,
}

Community Science College and Research Institute, TNAU, Madurai, India

\begin{abstract}
Jaggery is a natural sweetener, which is presently most preferred by the people. According to MSME 2018 report, sugar and jaggery (Gur) are the most important sweetening agents and are primarily extracted from sugarcane across the world. India is 2nd largest producer sugar in the world, whereas it is the largest producer of Jaggery and Jaggery products and consumer in the world. Workers employed in this industry are prone to various drudgery and occupational hazards. To study the effect of interventions in this industry, an exploratory survey on the work hazards and problems of women working in the jaggery processing units was recorded among sixty farm women by random sampling method. According to the results, jaggery ball making activity was defined as, the most drudgery prone activity among the various activities performed by women. A revolving stool, with back rest was designed as intervention and the effect of the intervention was analysed by experimental research design. Ten farm women were purposively selected for the study to evaluate the revolving stool, with back rest against the conventional method. The WERA score has reduced from 38 to 33 and showed a significant reduction $(P<0.05)$ in the physical risk factors of the women while using the designed stool. The physiological work load has reduced (working heart rate - $108 \mathrm{bpm}$ ) and the postural load has reduced due to the revolving nature of the stool. The designed revolving stool with back rest has resulted in reduction of postural discomfort of the women. Thus, solution with certain ergonomic design modifications and developments lead to viable well being of the women in agro based enterprises.

KEYWORDS: Jaggery, Women, Agriculture, Ergonomics\&posture
\end{abstract}

Received: Apr 08, 2020; Accepted: Apr 28, 2020; Published: Jun 10, 2020; Paper Id.: IJASRAUG20202

\section{INTRODUCTION}

India produces more than 70 per cent of the total jaggery of the world(Rao et al., 2007). As much as 40-45 per cent of sugarcane crop has been processed annually in to jaggery or brown sugar (Chand et al., 2011). Tamil Nadu is one of the leading producers of jaggery apart from sugar. Large numbers of jaggery production units are operating in the state, which has a great employment potential. Being a small scale processing unit, the jaggery ball making was considered as strenuous work involving women in all the activities. Women, while performing strenuous activities, they are more vulnerable to experience fatigue and thereby leading to absenteeism in work. The use of conventional stool resulted in various problems for the women and developed a need for change in the conventional stool. Revolving stool with back rest was designed as an alternative. This study thus focuses on the effect of the intervention, designed mainly in drudgery reduction of the women in jaggery processing units. 


\section{METHODOLOGY}

Four villages namely, Kondayampatti, Ayanampatti, Sembugudipatti and Thanichiyam of Vadipatti block of Madurai Districtwere purposively selected due to its large area of sugarcane production. Sixty jaggery processing units are present in the selected area which involves fifty percent of women labour. An exploratory research study was conducted among 60 farm women to understand the participation of women in jaggery processing, and the drudgery experienced by the women while performing the tasks. An experimental research design was adopted to study the impact of interventions in the study. Ten subjects (women) performing the selected activity for intervention was chosen for the study. Videos on the activities performed by the subjects in conventional and improved method was recorded. The effect of the intervention on the reduction in drudgery of women was analysed using observational methods such as the WERA tool and postural load of the women workers in jaggery processing units. The WERA tool cover the six physical risk factors including posture, repetition, forceful, vibration, contact stress and task duration and its involve the five main body regions such as shoulder, wrist, back, neck and leg (Rahman et.al.,2012). Polar V800 heart rate monitor was used to assess the physiological work load in both conventional method and improved method.

\section{RESULTS AND DISCUSSIONS}

\subsection{Identification of Drudgery Prone Activity}

Jaggery processing units involve six major activities performed by women labour. The activities involving major women are crushing of sugarcane for extracting sugarcane juice, carrying the crushed bagasse to the trolley, sun drying of the bagasse, cooling of the boiled sugarcane syrup, making jaggery balls and packaging. The results of the exploratory study conducted among women in jaggery making revealed the major drudgery prone activities ranked by women, as given in table 1 .

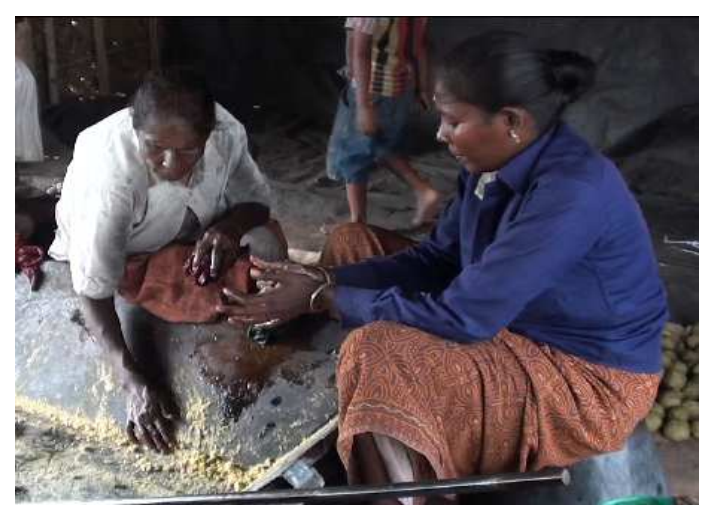

Conventional Method of Jaggery Ball Making Activity.

Table 1: Major Drudgery Prone Activities Ranked by Women

\begin{tabular}{|l|c|}
\hline \multicolumn{1}{|c|}{ Activity } & Drudgery Prone Activity* \\
\hline Jaggery ball making & I \\
\hline Drying of bagasse & II \\
\hline Carrying crushed bagasse & III \\
\hline Fueling of chulha & IV \\
\hline Cooling of syrup & V \\
\hline Packaging & VI \\
\hline
\end{tabular}

*Based on the drudgery assessment carried out using the Interview Schedule 
According to the table, jaggery ball making activity was ranked as the first major drudgery prone activity by the women in the processing units. While making jaggery balls, the workers had to sit on a low level box / stool without any back support and make jaggery balls using bare hands.

Table 2: Problems Reported by Women Workers while Performing Jaggery Ball Making

\begin{tabular}{|c|l|c|}
\hline Sl.No. & \multicolumn{1}{|c|}{ Problems Reported while Jaggery Ball Making } & Percentage (\%) \\
\hline 1. & Continuous work near hot environment (Chula) & 64 \\
\hline 2. & Persistent low back pain for prolonged time & 88 \\
\hline 3. & Burns and hardening of palm due to hot jaggery liquid & 75 \\
\hline 4. & Leg and knee pain while sitting in conventional stools & 72 \\
\hline 5. & Lack of comfortable sitting surface while jaggery ball making & 70 \\
\hline 6. & Constant sweating and neck pain while working & 58 \\
\hline
\end{tabular}

The problems reported by women workers while jaggery ball making is presented in table 2. Majority (88\%) of women reported persistent low back pain for prolonged time. Seventy five percent of the women reported burns in their hands and hardening of palm due to hot jaggery liquid. Knee and leg pain was experienced by seventy two percent of women while sitting in conventional stools/boxes.

Seventy percent of the women reported lack of comfortable stool /chair while jaggery ball making. Sixty four percent of them reported discomfort due to continuous work near the Chula (hot environment). Jackson and Rosenberg (2010) observed that the heat stress from exertion and environmental heat sources commonly resulted in physiological strain among workers in many occupational settings. Constant sweating and neck pain while working was reported by fifty eight percent of the women.

Thus, by considering the problems faced by women and to reduce the muscle strain experienced by women while jaggery ball making, a low level revolving stool with back rest was designed and the same was evaluated.

\subsection{Revolving Stool with Back Rest}

Relevant anthropometric measurements of the women were recorded and based on the measurements; a revolving stool with back rest was designed for the farm women. The stool aids support to the lower back region and the revolving nature of the stool helps in twisting and turning action while at work.

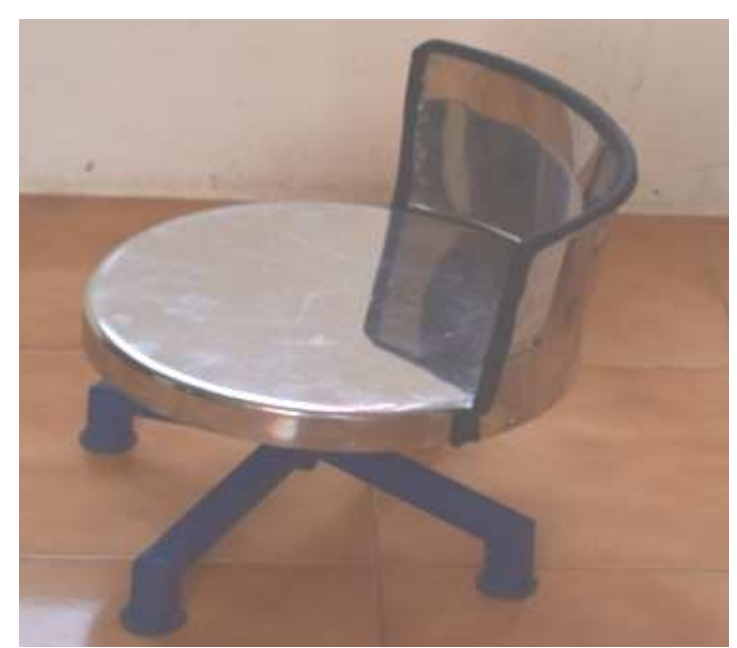

Revolving Stool with Back Rest 


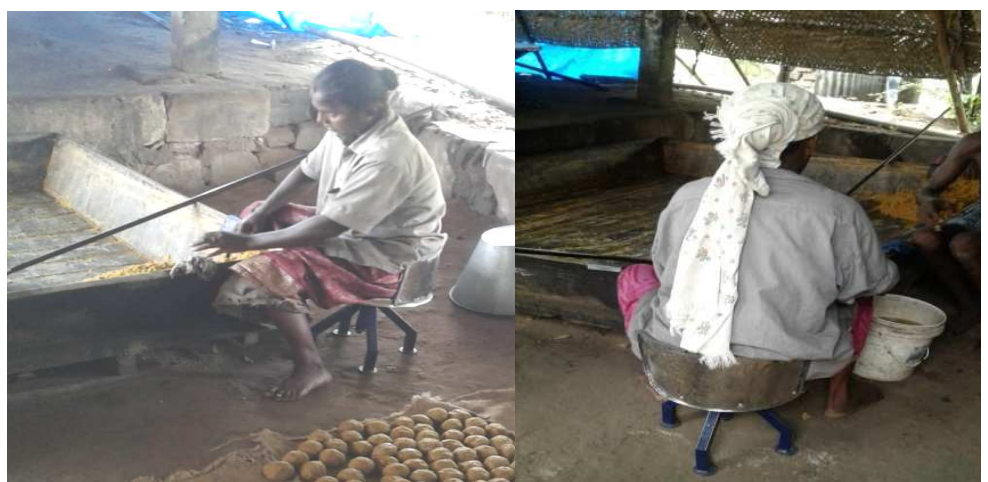

Women Performing the Activity using Revolving Stool with Back Rest.

Table 2

\begin{tabular}{|l|l|}
\hline \multicolumn{1}{|c|}{$\begin{array}{c}\text { Features Present in the Revolving Stool } \\
\text { with Back Rest }\end{array}$} & \multicolumn{1}{c|}{ Use } \\
\hline $\begin{array}{l}\text { Material used - stainless steel stool with } \\
\text { iron rod legs }\end{array}$ & Durable and stable to use for any body type \\
\hline Semi circular back rest & $\begin{array}{l}\text { For fit of the low back region of the women } \\
\text { and to avoid injury while working }\end{array}$ \\
\hline Revolving nature of the stool & $\begin{array}{l}\text { For easy access and twisting and thereby } \\
\text { reduce the strain in back and shoulder } \\
\text { regions }\end{array}$ \\
\hline
\end{tabular}

The experimental study on the effect of intervention i.e. revolving stool with back rest on jaggery ball making activity was carried out by introducing the designed stool, to ten women workers in the units. The general information on the age, work experience and BMI was recorded prior to the conduct of the study, and presented in table 3.

Table 3: General Information of the Selected Subjects Performing Jaggery Ball Making Activity

\begin{tabular}{|c|l|c|c|}
\hline Sl. No. & \multicolumn{1}{|c|}{ Particulars } & Mean & S.D. \\
\hline 1 & Age (Years) & 35 & 7 \\
\hline 2 & Work Experience (years) & 12 & 6 \\
\hline 3 & BMI & 23.06 & 2.3 \\
\hline
\end{tabular}

The mean age of the women was 35 years, with mean work experience of 12 years in this occupation. The mean Body mass index of the subjects was 23.06, which depicted that the women were belonging to normal BMI category. The WERA assessment tool, used to evaluate the effect of the designed revolving stool with back rest, is presented in table 4 .

Table 4: Average WERA scores of the women in Jaggery Ball Making

(Conventional Method and using Revolving Stool with Back Rest)

\begin{tabular}{|c|c|c|c|c|c|c|}
\hline \multirow{2}{*}{ Sl.No. } & \multirow{2}{*}{\multicolumn{2}{|c|}{ Physical Risk Factor }} & \multicolumn{2}{|c|}{ Conventional Method } & \multicolumn{2}{|c|}{ Revolving Stool with Back Rest } \\
\hline & & & \multirow{2}{*}{$\begin{array}{l}\text { Risk Level } \\
\text { Low }(1.5)\end{array}$} & \multirow{3}{*}{$\begin{array}{c}\text { Score } \\
3.5\end{array}$} & Risk Level & Score \\
\hline \multirow{2}{*}{1.} & \multirow{2}{*}{ Shoulder } & 1a. Posture & & & Low(1.6) & \multirow{2}{*}{3.5} \\
\hline & & 1b.Repetition & Medium(2) & & $\operatorname{Medium}(2)$ & \\
\hline \multirow[t]{2}{*}{2.} & \multirow[t]{2}{*}{ Wrist } & 2a. Posture & $\operatorname{High}(2.9)$ & \multirow{2}{*}{4.5} & $\operatorname{High}(2.9)$ & \multirow{2}{*}{4.1} \\
\hline & & 2b.Repetition & Medium(1.6) & & $\operatorname{Low}(1.1)$ & \\
\hline \multirow[t]{2}{*}{3.} & \multirow[t]{2}{*}{ Back } & 3a. Posture & $\operatorname{High}(3)$ & \multirow{2}{*}{6} & $\operatorname{Low}(1)$ & \multirow{2}{*}{2.4} \\
\hline & & 3b.Repetition & $\operatorname{High}(3)$ & & $\operatorname{Low}(1.7)$ & \\
\hline \multirow[t]{2}{*}{4.} & \multirow[t]{2}{*}{ Neck } & 4a. Posture & $\operatorname{High}(2.9)$ & \multirow{2}{*}{4.9} & $\operatorname{Medium}(2.3)$ & \multirow{2}{*}{4.2} \\
\hline & & 4b.Repetition & Medium(2) & & $\operatorname{Medium}(2)$ & \\
\hline \multirow[t]{2}{*}{5.} & \multirow[t]{2}{*}{ Leg } & 5a. Posture & Medium(2.6) & \multirow{2}{*}{3.6} & Medium(2) & \multirow{2}{*}{3} \\
\hline & & 5b.Repetition & $\operatorname{Low}(1)$ & & Low $(1)$ & \\
\hline 6. & Forceful & & Low(1) & 2 & Low(1) & 2 \\
\hline
\end{tabular}




\begin{tabular}{|c|l|l|l|c|c|c|}
\hline 7. & Vibration & & $\operatorname{Low}(1)$ & 2 & $\operatorname{Low}(1)$ & 2 \\
\hline 8. & Contact Stress & & $\operatorname{High}(3)$ & 6 & $\operatorname{High}(5.8)$ & 5.8 \\
\hline 9. & Task Duration & & $\operatorname{High}(2.9)$ & 5.9 & $\operatorname{High}(5.9)$ & 5.9 \\
\hline & Total Score & & 38.4 & & 32.9 \\
\hline & Paired t - test & \multicolumn{3}{|c|}{$14.578^{*}$} \\
\hline
\end{tabular}

$* * \mathrm{P}<0.01, * \mathrm{P}<0.05, \mathrm{NS}-$ Non Significant

In conventional method of jaggery ball making activity, the WERA score of the human factors indicated high risk in back (6) followed by neck (4.6) and wrist (4.5). Sitting for prolonged time in a box with no back support has resulted in increased level of risk of musculoskeletal discomfort in the lower back region. Continuous twisting and turning activity resulted in postural discomfort in low back. Among the external factors, lack of proper tool and prolonged time of work lead to increase in scores of contact stress (6) and duration (5.9). The total mean WERA score of the conventional method was 38.4, which indicated that an immediate action is needed to change the task.

The impact of using the revolving stool with back rest was assessed using the WERA tool. Since the stool has a back support, the human factor score of back reduced to 2.4 and facilitated twisting with less discomfort. This was followed by reduction in the score of neck (4.2), the revolving action in the stool reduced muscle strain in the neck. The total mean WERA score of jaggery ball making activity with use of revolving stool with back rest was 32.9. This showed that the improved method i.e., the revolving stool with back rest is recommended for use, and it reduces the drudgery experienced by women working in jaggery ball making activity.

Paired t- test was used to access the reduction in discomfort level of muscles using WERA. It was observed that there is a significant reduction $(\mathrm{P}<0.05)$ in the WERA score while comparing with the conventional method. The physiological work load of women was recorded in conventional method, and while using revolving stool with back rest is presented in table 5 .

Table 5: Physiological load of women while Jaggery Ball Making

\begin{tabular}{|c|c|c|c|}
\hline \multirow{2}{*}{\multicolumn{2}{|c|}{ Heart Rate }} & Conventional Method & Revolving Stool with Back Rest \\
\hline & & Avg. & Avg. \\
\hline 1. & Resting Heart Rate & 80.7 & 81.2 \\
\hline 2. & Working Heart Rate & 113.3 & 108.6 \\
\hline 3. & Recovery Heart Rate & 93.7 & 94.8 \\
\hline \multicolumn{4}{|c|}{ Cardiac Cost } \\
\hline 1. & Cardiac cost of work (CCW) & 978 & 822 \\
\hline 2. & Cardiac cost of Recovery (CCR) & 55 & 68 \\
\hline 3. & $\begin{array}{l}\text { Total cardiac cost of work } \\
\text { (TCCW /duration) }\end{array}$ & 1043 & 890 \\
\hline 4. & PCW & 26.07 & 22.25 \\
\hline 5. & Work Load Category as per HR* & 3.8 & 3.2 \\
\hline
\end{tabular}

*Work load - 5- very heavy, 4- heavy, 3- moderate, 2-light, 1-very light.

The physiological work load of the women involved in jaggery ball making activity was assessed using conventional stool and improved revolving stool with back rest. The average working heart rate was 113.3 bpm in conventional method, and was 108.6 bpm using the revolving stool with back rest. The mean cardiac cost of work (CCW) was observed to be reduced while using the revolving stool with back rest. Though there is reduction in the PCW (Physiological cost of work) while using the revolving stool withback rest, the work load categorization rated by the women after using the stool was only in moderate level of work load. 
Table 6:Posture Analysis of Neck and Trunk while Jaggery Ball Making

\begin{tabular}{|c|c|c|}
\hline $\begin{array}{l}\text { Degree of Neck deviation as per plumb line compared to } \\
\text { erect posture }\end{array}$ & Conventional method & $\begin{array}{c}\text { Improved } \\
\text { method }\end{array}$ \\
\hline $\begin{array}{l}0^{0}-10^{\circ}+1 ; 10^{\circ}-20^{\circ}+2 ; 20^{\circ}-\text { and forward bent }+3 ; 20^{\circ} \text { and } \\
\text { backward bent }+4\end{array}$ & +3 & +1 \\
\hline $\begin{array}{l}\text { Degree of Trunk deviation as per plumb line compared to } \\
\text { Erect Posture }\end{array}$ & $\begin{array}{c}\text { Conventional } \\
\text { Method }\end{array}$ & ImprovedMethod \\
\hline $\begin{array}{l}0^{0}-10^{0}+1 ; 10^{0}-20^{0}+2 ; 20^{\circ} \text { - and forward bent }+3 ; 20^{\circ} \text { and } \\
\text { backward bent }+4\end{array}$ & +3 & +1 \\
\hline Postural Load Rating * & 1.4 & 4.2 \\
\hline
\end{tabular}

Posture load - 5- very comfortable, 4- comfortable, 3- moderate, 2-discomfort, 1-very uncomfortable.

The neck and trunk posture adopted during the conventional method of jaggery ball making was forward bent $(+3)$ and (+3), respectively. This has reduced to +1 in neck and trunk region due to the introduction and usage of revolving stool with back rest support. Hoy et al., (2010) has said that in occupational settings, people with jobs that require manual materials handling are at increased risk for low back pain. The average postural load was very discomfort level (1.4) in conventional method. While using the revolving stool with back rest, the postural load rating increased to 4.2 i.e., comfortable to work. The frequent rotation motion and twisting of back is completely reduced due to the revolving nature of the stool.

\section{CONCLUSIONS}

The jaggery making industries is considered as an efficient and growing industry in current scenario of the world, focusing on alternative natural sweetener for sugar. The jaggery processing industries are more popular in regions of Madurai district, emphasizing areas of higher sugarcane production. The women participate in fifty percent of activities in jaggery processing units, which involve five major activities. Among the various tasks performed, jaggery ball making activity was considered as more tedious drudgery prone activity by the women. Revolving stool with back rest was designed to reduce the drudgery of women. The study involved ten women, purposively selected for evaluating the designed stool. The results of the study revealed that there is reduction in the muscle strain and physiological work load of the women. Effective simple solution for agro based small enterprises would sustain their livelihood, and to develop the viability of the enterprise. 


\section{REFERENCES}

1. Chand K., Shahi, N.C., Lohani, U.C. and Garg, S.K..(2011). Effect of storage conditions on keeping qualities of jaggery. Sugar Tech. 13(1).81-85.

2. Hoy, D., P. Brooks, F. Blyth and R. Buchbinder. (2010). The Epidemiology of Low Back Pain. Best Practice \& Research in Clinical Rheumatology., 24: 769-781.

3. Jackson and Rosenberg. (2010). Preventing Heat-Related Illness Among Agricultural Workers. Journal of Agro medicine. 15:200-215.

4. MSME. (2018). A status report on Khandsari sugar/Jaggery. Government of India. 4-9.

5. Rahman, M.N.A., M.R.A. Rani, and M.J. Rohani. (2012). Investigation of work-related musculoskeletal disorders in wall plastering jobs within the construction industry. WORK: A Journal of Prevention, Assessment and Rehabilitation. 43 (4), $507-$ 514.

6. Rao, P.V.K.J, Das, M. and Das S.K. (2007). Jaggery- A traditional Indian sweetener, Indian Journal of Traditional Knowledge. 6(1). 95-102.

7. Pawar, D., Unde, P., \&Kanawade, V. Studies on Preparation of Jaggery Granules With Nucleation.

8. Anamica, M., \&Sujeetha, T. Determining The Empowerment Needs of Migrant Rural Youth to Attract And Retain In Agriculture.

9. Suseela, K., \&Chandrasekaran, M. Growth and Instability in Dryland Agriculture of Andhra Pradesh.

10. Kv, R., \&Kazi, S. Urban Agriculture in Cuba and Exploring Possibilities with Reference to Urban India. 

